\title{
The Puck Project: A Shakespeare Performance and Ethics Program for Kids
}

\author{
John Gulledge, Emory University \\ Kelly Duquette, Emory University \\ Mary Taylor Mann, Emory University
}

Snout: O Bottom, thou art changed. What do I see on thee?

Bottom: What do you see? You see an ass-head of your own, do you?

Quince: Bless, thee, Bottom, bless thee! Thou art translated.

A Midsummer Night's Dream, 3.1.104-106

When Peter Quince observes Bottom's new, translated form at the beginning of Act 3 in $A$ Midsummer Night's Dream, he likewise observes a primary preoccupation of Shakespeare's work. Quince is also echoing his fellow actor's observation a few lines earlier: "Thou art changed!" Indeed, Bottom has been "carried across" à la the Latin translatio, a carrying over that echoes the many translatable acts, behaviors, emotions, texts, and performances of the play. He is still Bottom, of course, but transformed and transferred. Conceptually, this praxis of change should be read as discrete from transliteration, which suggests a one-to-one swap. Instead, translation signals to an audience, and to the other actors in the play, the important quality of same but different. As a guiding method of The Puck Project, translation is a powerful framework for pedagogical aims such as "transfer" and "carrying over." Participants become agents of transfer while also, through acts of performance and play, become "carried across" not at all unlike Bottom's own dramatic transformation. If the forest of Midsummer represents a kind of green world of mutable meanings, semantic slippages, and safe simulation, then this pedagogical program of translation engenders a spontaneous green world where participants can explore various modes of being. Taken in this way, translation expands beyond language and text.

When teaching or using Shakespeare in any pedagogical setting, questions of applicability and relevance arise. These questions come almost always from students, but occasionally they are posed most emphatically by hesitant educators. Their reluctance, we admit, is not totally unfounded: Why teach with late $16^{\text {th }}$ century drama when working with elementary 
school-aged students of the $21^{\text {st }}$ century? How can Shakespeare speak to the lived realities that face children today? Does Shakespeare, as Jane Coles suggests, alienate students with diverse backgrounds, leading them to feel confused and frustrated? (Coles 64). ${ }^{1}$ The concerns raised by these questions are almost always assuming Shakespeare studies privileges the text above all else. In the past, this emphasis on the language as it was written was the dominant thrust of teaching and using Shakespearean drama. Increasingly, however, educators have begun to turn to performance-based pedagogies, noticing at last the imbedded somatic and cognitive impulses within each play. With these questions in mind, we set out to center the experience of young actors in order to collaboratively produce an adaptation of A Midsummer Night's Dream. This collaboration took many forms, including pantomime, ongoing script revision, and a method developed by Shakespeare and Company called "dropping and feeding." What resulted was The Puck Project, a performance-based summer program for K-6 learners in partnership with a nonprofit agency that supports homeless families in Atlanta, GA, called Nicholas House.

At the heart of The Puck Project is a desire to translate Shakespeare and performance with young actors. This act of translation takes many forms and serves a variety of roles for the program. Not least among these forms is fostering a translation into lived experience-precisely what critics of early modern drama in general education find the most dubious. Though a small sample and only anecdotal, The Puck Project confirmed what others have noticed for some time now: emotions like "love, hate, awe, tenderness, anger, despair, jealousy, contempt, fear, courage, wonder" (Gibson 3$)^{2}$ pass over and between boundaries of identity and are the lifeblood of theatrical performance. Shakespeare, perhaps, knew this better than any of us. While being forced by Athenian law to marry someone you do not love is far-fetched to elementary schoolers, experiencing conflict with parents and guardians is not. The quarrel between the fairy queen and king is certainly fantastical and strange, but disagreement and resolution are a part of everyday life. The wandering band of amateur actors rehearsing in a magical forest is far from commonplace today, but the urgency for community and strong interpersonal relationships is as pressing today as it has ever been. Like Chris Holland, we argue that "drama is a vehicle through which children can safely explore and identify with a story and its characters [in order to] build and express empathy, make decisions," and engage in conflict resolution, and the works of Shakespeare in particular demand the creative and emotional labor of translation (535). 


\section{Theoretical Inclinations}

\section{Translation and Performance}

Successful Shakespeare pedagogy de-centers the dramatic text in favor of the learner's lived realities. This may appear to be an odd claim, given the shared celebration of Shakespeare for the language itself, but the plays already lend themselves to unique interpretation and performance. For instance, Rex Gibson argues that the play's ambiguities provide the soil in which studentactors may create their own meaning and experience. We agree that "each student brings his or her own culture to every lesson. That rich variety of culture is a resource that Shakespeare lessons can celebrate and employ rather than dismiss" (Gibson 9). Instead of causing frustration or alienation, a learner-centered approach places student-actors in the thick of things-forcing them to engage in both aesthetic performance and social drama simultaneously.

By aesthetic performance, we mean the highly self-aware and artificial performances you normally get on the stage. Social drama refers to Victor Turner's observation that everyday life mirrors the rise and fall of a theatrical event. For Turner, it consists of the "units of aharmonic and disharmonic social process, arising in conflict situations" (Turner 74). While social drama is most apparent during moments of social strife, theatrical blueprints of performing the self within a community persist beyond situations of heightened tension. More recently, Richard Schechner has conceptualized aesthetic and social drama as the difference between cultural performance and the performance of culture. The former refers to something that is "staged," like the theater; it is a performance by nature. Performing culture, on the other hand, describes a behavior or ritual that can be analyzed and read as a performance (Schechner 36). While they are different in many ways, most notably with regards to context and intentionality, they are the raw source material for the other. In other words, as both Turner and Schechner suggest, the scripts by which people perform in their everyday lives are directly informed by the representational performances they consume, and the aesthetic, staged performances of the theater or in film draw on the lived experiences and social interactions of those same people. The theory of social drama then informed the way we approached the reality of our actors' experiences with homelessness. While we did not solicit personal experience from program participants, we invited these stories to inform their unique translations of the script. This means, of course, that actors were also invited to consider how the script informed their everyday lives. For example, in a mini-lesson on expressing emotions, actors used their own experience as source material to compose a skit. A 
group of male actors pantomimed a basketball scene, in which one player failed to sink a gamewinning shot at the buzzer. To show his embarrassment, he slumped his posture and turned away from his fellow players. His teammates pointed and jeered in a hyperbolic display of humiliation that parodies masculine bravado. In this moment, we observed their exposure to scripts of masculinity and competition play out in their performance. We then repurposed their lived experience of these scripts to inform a subsequent performance workshop with Act 4, Scene 5 from Troilus and Cressida. At this point in the play, Hector confronts Achilles in the Greek camp the night before their duel. To center the actors' social context in this scene, we invited them to consider the duel as a sporting event in a stadium rather than on a battlefield. We preserved much of Shakespeare's original text so that when the actor playing Hector admonishes Achilles, “O, like a book of sport thou'lt read me o'er," the previous skit echoes in the reframing of this new scene. The echo is heard in the word "sport" and lived experience and aesthetic performance at once become indiscernible. The basketball scene provided evidence that our actors acknowledge an ethic of sportsmanship that recovered a more empathetic translation of the scene between Hector and Achilles. In this way, their lived experience is carried over to Shakespeare's text as a mode of transfer.

Along similar lines but with an interest in literacy and interpretation, Edith Grossman argues how translation is a kind of "interpretive performance" where the actor/translator "performs" the source text, perceiving the author's voice while simultaneously transforming it into other modes, that is, hearing it in her own voice (Grossman, 11-2). Interpretive performance, then, as opposed to text-only literacies, uncover and conjure insistent variations. In the face of such performed and translated ambiguity, all sense of a single, "original" meaning as well as its hierarchical priorities quickly recede. ${ }^{3}$ Unlike only reading A Midsummer Night's Dream, performing the play enables an exploration of the actors' everyday lives - the performances they engage with day to day-all with the reverberation and echo of Shakespeare. Much like the plays themselves, performing translation asks us

to stay at the edge of what we know, to put our own epistemological certainties into question, and through that risk and openness to another way of knowing and living in the world to expand our capacity to imagine the human (Butler 228). 
In this way, "interpretive performance" creates an opportunity for the child to explore the self and her relationship to others.

In order to foster such an opportunity for the performance of translation, we turned to research in early childhood education to inform pedagogies of performing translation. Bob Barton and David Booth, among others, have suggested that

\begin{abstract}
Making sense of a story demands that students apply their own experiences to those in the story. The teacher must constantly help the children go back and forth between their own stories and their own responses, translating the experiences of the story into the context of their own lives (135).
\end{abstract}

Drama, then, allows the children's “own subjective worlds to come into play, helping them understand the meanings of the story as they live through the drama experience" (Barton and Booth 136). Within the field of education, play assumes several forms. As Joan Youngquist and Jann Pataray-Ching explain, one perspective describes play as "an enjoyable, self-amusing activity," such as two children on the playground immersed in a lightsaber duel (172). Other schools of thought describe play as an activity, with "an educational focus" such as a child in a preschool environment investigating sharks as part of project work (Youngquist and PatarayChing 172). The Puck Project's vision of play, however, most closely aligns with Doris Bergen Sponseller's conception. Sponseller explains that genuine play resides within the child, it is controlled by the child's acts, driven by the child's motivations, and based on the child's sense of reality (12). Puck Project actors, as will be expounded upon in later sections, asserted autonomy over their dramatic choices and vetted these creative decisions collaboratively with their fellow actors. Early childhood psychologist, Angeline Stoll Lillard, develops this idea further and asserts that children develop theories about their world through different play activities contributing to their theories of mind (27). Through numerous experiences of play, children develop the foundation for other forms of development connected to academic learning, such as emergent literacy into fictional story telling (Neuman and Roskos 100-1). These studies form the basis for bringing dramatic practices into elementary classrooms. Play and dramatic experiences not only supplement early literacy pedagogies in meaningful ways, but provide children simulated opportunities to develop their worldview within the safe space of the classroom. 


\section{Empathetic Imagination}

Invoking Aristotle's Poetics, Martha C. Nussbaum describes the "knowledge of possibilities" literature offers to its readers (86). Engagement with the arts - especially literature, which has the capacity to represent for its readers a rich array of circumstances, problems, and experiences of different and diverse people - is a quality, Nussbaum argues, essential to the formation of the informed and compassionate world citizen. Nussbaum shares Judith Frank's view that literature can "expand our sense of what it's possible to think and feel" (133). At a young age, exposure to stories and storytelling, or "narrative play," cultivates a sense of wonder in children about the interior workings and internal experiences of other people (and animals or anthropomorphized objects in the case of much of children's literature). Nussbaum explains that through storytelling children learn the imaginative skills necessary to relate the self and the other: "the conclusion that this set of limbs in front of me has emotions and feelings and thoughts of the sort I attribute to myself will not be reached without the training of the imagination that storytelling promotes" (89). Further developed through the creative work of storytelling is the "narrative imagination," or the child's sensitivity to the infinite possibilities of human experience, including experiences that may be different from or not readily relevant to the child: "The habits of wonder promoted by storytelling thus define the other person as spacious and deep, with qualitative differences from oneself and hidden places worthy of respect" (Nussbaum 90). From this imaginative space of wonder, recognition, and respect that literature and storytelling provide comes an empathetic relationship with the other and a sense of community. Within this community, Nussbaum explains, one "cultivates a sympathetic responsiveness to another's needs, and understands the circumstances that shape those needs, while respecting separateness and privacy" (90).

One particular realm of imaginative storytelling and narrative play is that of performance and drama. The capacity for empathy that dramatic performance provides is a topic of interest to both scholars of primary education and scholars of professional higher education. Education scholars Jeffrey D. Wilhelm and Brian Edmiston utilize drama as a method of performancebased learning in which elementary- and middle-school-aged students are challenged to explore diverse viewpoints and confront their own beliefs and actions. Wilhelm and Edmiston invoke Dorothy Heathcote, asserting that "drama 'protects students into experience' so that they are safe to imagine, explore, and confront possible ways of being in world" (56). Wilhelm and Edmiston 
envision their drama-infused pedagogy as an ethical project in which a student's relationship with others is central to the formation of the self:

Students do not just act in drama - they also reflect on the meanings of actions as they consider the consequences for different people. Reflection is dialogic when students evaluate actions from the point of view of the person affected. Students can evaluate not only others' actions, but critically — for the development of an ethical self - in drama they can evaluate their own actions (60).

Like Nussbaum's “knowledge of possibilities," Wilhelm and Edmiston's theory of performancebased learning requires a turn toward the other via the imaginative engagement with diverse voices and perspectives while simultaneously relating the experience of the other to the self.

In the context of professional higher education, Gretchen A. Case and Daniel J. Brauner, who advocate for the integration of performance studies theory and methods into medical curricula, argue that the "academic discipline of performance studies offers a paradigm not only for teaching doctors how to 'act' in a more truly empathetic and compassionate manner but also for analyzing, and thus evaluating and improving, human interactions in the medical environment" (159). Performance-based learning is less about prescribing action or instructing students to behave empathetically, instead, performance methods are used to provide medical students with the skills they need to navigate the complex and difficult interactions they will inevitably have with patients and families during the course of their careers. The capacities associated with performance are necessary for the formation of what Case and Brauner call the "empathetic imagination" (159). Historically, the concept of the empathetic imagination derives from eighteenth-century philosophical discourse relevant to sympathy, the "sympathetic imagination," or "imaginative identification" (Herdt 531-32). Case and Brauner define empathetic imagination as the "cognitive skill set that helps one to imagine the experiences and responses of another person" (159). Just as Nussbaum's narrative imagination cultivates a "knowledge of possibilities" in children as they engage in storytelling and narrative play, empathetic imagination allows for adaptive interpretation and response to the infinite possibilities of human experience and interaction in the clinical setting, or any setting.

Borrowing from both Wilhelm and Edmiston's research and Case and Brauner's theory, the Puck Project adapts the empathetic imagination for the elementary classroom. For children as well as doctors-in-training, performance-based learning that exercises the empathetic 
imagination is an "inventive process for generating ideas, solving problems, and creating possibilities from a perspective that is firmly situated in a wish to understand [another's] embodied experience" (Case and Brauner 160). The skills and capacities children acquire during the process of engaging with and performing a play—building a community, collaborating to create and express ideas, using voice and body to communicate, acknowledging and addressing other's emotions, and managing one's own emotions - may be translated into emotional intelligence and recognition capacities that have ethical implications. Empathetic imagination requires close attention to the lived experience of another person, the position of the self in relation to that person, and the differences in perspective or point of view. Tethered to this awareness is a sense that such differences are ethically significant, that the imaginative act of performance and the human act of empathetic communication cannot proceed without attention to such perspectives.

Embodied Translation

Recent studies in psychology elucidate the profound link between physical movement and emotional sensitivity. Thomas Fuchs and Sabine C. Koch identify a growing body of psychology research that demonstrates that bodily sensations, postures, gesture, and expressions are "inherent components of emotional experience and tacitly influence the evaluation of persons, objects and situations as well as memory recall" (Fuchs and Koch 1). From this body of research, Fuchs and Koch define and describe the phenomenon of embodied affectivity, or the circular relationship between emotion and physical motion in which the body "functions as a medium of emotional perception" (1). The body experiences emotions via various physical sensations that correspond to nervous and muscular activity, such as an elevated heart rate, sweating, a clenched jaw, or a slumped posture. These sensations and corresponding physiological activity comprise what Fuchs and Koch call the "bodily resonance" of emotion (Fuchs and Koch 3). Bodily resonance determines and is determined by the emotional feeling itself and may prompt instances of "interaffectivity," in which the body is affected by and may experience the intensity of another body's emotions via its bodily expressions, postures, or gestures (Fuchs and Koch 5). For Fuchs and Koch, this interaffectivity forms the "bodily basis of empathy and social understanding" (5). Emotions may be better understood as "shared states" experienced between bodies rather than interior states that may only be experienced on an individual basis or deciphered in others: "There is a bodily link which allows emotions to 
immediately affect the other and thus enables empathic understanding without requiring a Theory of Mind or verbal articulation" (Fuchs and Koch 7). Theatre performance is uniquely suited to build these deep empathetic faculties.

For our project of translation, pantomime served as a cornerstone because it required actors to embody the text. Cecily Berry, late British theatre director and vocal coach at the Royal Shakespeare Company, explains that to help actors understand their lines, they need to access the "tactile nature of the sound" through physical movement activities designed to release the energies latent in Shakespeare's language (104). As Astrid Yi-Mei Cheng and Joe Winston suggest in their work with English as a Second Language (ESL) students, "physicalizing" Shakespeare's lines in order to "grasp the spirit of the picture" illuminates the interplay between "image and intention" (548). For students learning a new language or learning to read, a personalized, embodied connection between the actor and the text can inspire new interpretations and perspectives. Translating meter, rhythm, consonants, or vowels into directional movement, physical restraint, or the empathetic action of shaking someone's hand, for example, creates a memorable, personal connection between player and language.

\section{The Puck Project: Theory and Goals}

The Puck Project arose out of a desire to incorporate public scholarship into our graduate study. All too often, graduate study is a self-centered endeavor that reifies the continued isolation of the academy from its wider communities. Taking its inspiration from other community-based Shakespeare programs, such as Shakespeare Behind Bars and Feast of Crispian, ${ }^{4}$ The Puck Project is, at its core, committed to dissolving the arbitrary boundary between scholarship and civic engagement. We found our community partner in Nicholas House. Each summer, Nicholas House hosts a kids' summer camp, Camp Nicholas, and invites members of the community and local organizations to lead various educational and recreational activities. As a part of Camp Nicholas, The Puck Project developed a four-week Shakespeare performance program. The primary purpose of The Puck Project is to provide a space of learning, growth, and creativity to children through the works of Shakespeare. We also sought to create a space in which children were encouraged to confront the ethical questions present in the dramatic text itself, but more importantly the ethical dilemmas that surface in the act of performance. The experience of 
moving from creativity to ethical deliberation is facilitated through "play." Within the context of play, actors guide themselves and each other through various ethical scenarios.

We distilled our purpose into a three-part goal: first, taking seriously the ethical toolkit one acquires when embarking upon a journey of performance, actors are then invited to practice empathetic imagination, which translates into emotional intelligence. Of course, this purpose was not to instruct our students toward a certain kind of moral thinking, nor was it to pore endlessly over the many different ethical conflicts that occur during the course of A Midsummer Night's Dream. Instead the aim of the The Puck Project was to engage and cultivate skills relevant to functioning within a community, formulating and expressing ideas as a team, engaging in constructive dialogue, reading and responding to the emotions of others, and accessing and attending to emotions in oneself - all of which fall squarely within the rubric of performance.

As guest facilitators at Camp Nicholas we were able to schedule 16 meetings over a period of four weeks, and our curriculum consisted of four one-hour lessons each week. The program culminated in a production of A Midsummer Night's Dream for the actors' friends and family. Morning lessons utilized acting exercises and games, team-building activities, and artsbased learning. Afternoon sessions focused on learning the play and rehearsing for the final performance. Two lessons featured workshops led by teaching artists with the Atlanta Shakespeare Company, a professional theater group specializing in early modern drama with an established education program. The reflective component of the curriculum consisted of daily journaling. Reflective writing activities were especially meaningful for the community-building effort as we took the time each week to read and respond to actor reflections.

Elements of backwards design informed The Puck Project's approach to daily lesson planning. In Understanding by Design, Grant Wiggins and Jay McTighe remind us that lessons, units, and courses should be "logically inferred from the results sought," not derived from the "methods, books, and activities with which we are most comfortable" (14). Wiggins and McTighe liken this approach to travel planning: frameworks should provide a "set of itineraries deliberately designed to meet cultural goals" rather than a "purposeless tour of all the major sites" (14). The programmatic curriculum thus developed via a three-stage approach: (1) identify desired results; (2) determine acceptable evidence; and (3) plan learning experiences and instruction (Wiggins and McTighe 17-18). In the first stage, we determined what actors should know, understand, and be able to do by summer's end. Cultivating the actors' empathetic 
imaginations was central to the project. To serve this long-term goal, we devised a list of "I can" statements, or learning targets in child-friendly language (i.e. "I can give and accept feedback on my own and others' work;" "I can express and communicate my feelings through art and design;" or "I can use my imagination to creatively solve problems on stage and in real life"). Because The Puck Project was integrated into a summer camp and not a traditional classroom, our data collection strategies strayed from formal assessment methods. To determine if actors had achieved the desired results, we decided in stage two of backwards design that journaling would best allow students to reflect on their dramatic experiences in an informal, individualized way. At the end of each session, actors responded to an essential question aligned with the daily learning objective (i.e. "Which character in the play do you most identify with and why?"). Journals offered an additional benefit: arts practitioner could provide meaningful responses to journal entries and engage the actor's thoughts, feelings, and ideas intimately and in real-time. With objectives and assessment strategies established, arts practitioners then selected performance activities in the final planning stages that aligned with the daily learning objective. For example, on a day when the actor's goal was to "explore emotion through movement and expression" and to "demonstrate the difference between 'indicating' and 'acting," actors engaged in an activity called "the many faces of mad." In this exercise, actors pull feelings out of a hat and "try on" stereotypical facial expressions or gestures. In exploring the movement of anger, for example, the actor might experience the inauthenticity of a stereotypical movement like shaking one's fist. The arts practitioner's job is to follow up with the actors in whole-group discussion, asking each to what extent these exaggerated postures accurately captured an image and feeling of anger. In the next step, actors were asked to embody the emotion again with the added direction of remembering or imagining a familiar moment of frustration. Actors reflected on the changes they experienced over the course of the activity during journaling time. Beginning with the end in mind, planning activities in this way gives actors the opportunity to digest daily learning objectives and generate relevant applications to their own experiences.

In order to facilitate our performance goals, we had to adapt A Midsummer Night's Dream into a more accessible text. This first step began with early childhood literacy in mind. The script's language needed to meet actors at their respective stages of reading development. ${ }^{5}$ Reworking a high school script to accommodate K-6 actors involved what Jakobson refers to as intralingual translation, or rewording, "an interpretation of verbal signs by means of other signs 
of the same language" (139). Intralingual translation is akin to the process of meaning making, wherein an "array of linguistic signs is needed to introduce an unfamiliar word" (Jakobson 139). But, as Alexander Huang points out, this kind of translation involves artistic creativity and is not simply a "workshop of equivalences" (68). This workshop of equivalences, or what we previously referred to as an act of transliteration, privileges the text and reduces the adaptation to an economy of words. In keeping with the goals of the project, we prioritized character motivations, ethical dimensions of the play, performance length, and the number of actors capable of reading (and memorizing, to some extent) a series of lines. In other words, our adaptation of the play displaces Shakespeare's written text to foreground our actors' emotional and developmental contexts. A developmentally-appropriate script necessitated a hybrid form to accommodate a spectrum of early readers and to work within the parameters of camp logistics. Fluent and transitional readers participated in scenes of traditional dialogue, while emergent readers engaged the text via pantomime with another actor or arts practitioner providing voiceover narration. Minimal recitation of lines for emergent readers helped alleviate frustrations that often accompany the challenges of learning to read, and mitigated the anxieties of the youngest actors, performing the spoken word in front of an audience for the first time. The process resulted in a collaborative adaptation: one the one hand, arts practitioners were responsible for generating a more amenable script, and on the other, actors bodied forth the mutability of the lines via shared performative decisions.

\section{Puck in Practice}

Moving to Translate

Like many amateur acting troupes, Shakespeare's rude mechanicals have difficulty finding a place to rehearse after a long day's work. They trek into the fairy-ridden forest away from the distraction of friends and colleagues to focus on their Ovidian rendition. The rude mechanicals of our production faced a similar task. Because their scenes were entirely pantomimed, their rehearsals necessitated a quiet, separate space from their peers (the hallway) wherein they could experiment with the silence of nonverbal performance. Although pantomimed scenes were ultimately accompanied by voice-over narration, our rehearsals began with the traditional dialogue of the adapted script. 
While reading through a scene, actors, arts practitioners, and camp counselors paused after each line to imagine how the actors' movements might capture the image and intent of the language. This process accessed both the actors' empathetic imaginations and embodied translation. In the first act of the play, for example, the mechanicals gather at Peter Quince's house to discuss role assignments. The lion's part, assigned to Snug, becomes the object of Bottom's affection: “Let me play the lion too: I will roar, that I will / do any man's heart good to hear me..." (1.2.58-9). Actors then imagined or recalled instances when they experienced a similar predicament. During group discussion, several actors offered memories of the classroom, encounters with relatives, or experiences playing sports when they desired the same object or task as someone else. One of our youngest actors, for instance, recalled feelings of frustration when her teacher at school chose another student as line leader: "Everyone was raising their hands, and I raised my hand first, but she got it." This is striking because the experience of Bottom during this scene conjures up a former lived experience of the actor. Others participating in this scene responded by sharing similar experiences. This peer-to-peer dialogue generated a conversation about translating experience into performance. As a community, student-actors repurposed the eagerness of hand raising in order to translate an image of shared desire among the rude mechanicals. What does it look like when an overly eager student raises their hand? Student-actors shook their hands furiously in the air, some fell out of their chairs, and others stretched their arms as high as they could fathom, eking every last millimeter of air over their peers. This kind of physical movement, they collaboratively determined, should inform Bottom's maneuvers across the stage.

In reflection, the actors offered fair and equitable solutions to this problem: "Quince could have a try-out to see who the best lion is and then decide;" or "Bottom could try to understand that Snug is nervous and has a hard time remembering lines, so performing the lion's part would be best for him." As actors progressed through the scene, they quickly learned that Quince fails to entertain Bottom's proposition: "You can play no part but Pyramus" (1.2.70). Originally siding with Snug, actors then wondered how Quince's authoritative stance might affect Bottom's feelings: "He doesn't even give him a chance." Witnessing the scene's failure to reach an equitable solution, student-actors placed themselves in unlikely shoes, and empathized to some extent with Bottom's character. 
However, collaborative efforts to stage pantomimed scenes did not always transpire so smoothly. In the final act of Midsummer, the rude mechanicals perform the tragic events of Pyramus and Thisbe's love in front of the Athenian court at Theseus' palace. In daily rehearsals, the actor portraying Snug-cum-lion offered a roar respectable enough to gain the audience's affections. In dress rehearsal, however, the actor liberated a crescendo of sound so shaking and unexpected, that it sent the actor playing Flute/Thisbe flying across the classroom in search of protection beneath a classroom table. Once laughter subsided and order was restored, actors faced a difficult decision: should Snug unleash this version of the beast in the final production, or revert to the tempered interpretation? The group concluded that Flute/Thisbe's reaction ironically realized the mechanicals worst fears:

You, ladies, you, whose gentle hearts do fear

The smallest monstrous mouse that creeps on floor, May now perchance both quake and tremble here, When lion rough in wildest rage doth roar.

Then know that I, one Snug the joiner, am

A lion-fell, nor else no lion's dam;

For, if I should as lion come in strife Into this place, 'twere pity on my life. (5.1.214-221)

Witnessing their peer's real and visibly identifiable moment of surprise initiated the group's creative conversation about the accurate portrayal of fear. Because the outburst was met by both fear and laughter, we prompted students to consider, "Why did Snug's decision make some of you laugh and some of you scared?" One student responded, "Last time she wasn't so loud, and I was really surprised." Snug's improvisation created an incongruity between performances which registers as both comical and unsettling. The actors then discussed which of Snug's interpretations best captured the problem of the lion's roar. Like the rude mechanicals, the actors were concerned with audience reception, ultimately wanting to make their friends and family laugh. Imaging the experience of their audience, caused the rude mechanicals to revisit the comic elements of the scene and enriched their interpretation of the lines. 


\section{Team Story-Building}

In a lesson on narrative and context, actors worked in teams to complete the Team StoryBuilding game. Small groups of actors stood in circles and read a sentence from a notecard that would serve as the opening line of the group's team story. After the first sentence, the actors went around the circle each providing only one additional word to continue the story. The storybuilding continued several times around the circle as the actors quickly realized the difficulty of restricting themselves to only one word per round. The desire to create a cohesive narrative was apparent in the actors who offered word suggestions, critiqued the word choices of their peers, and proposed alternatives. One actor, the youngest actor in the troupe (four years old), stood holding the hand of an older actor. For the first few rounds in the game, the youngest actor would pause at her turn until the older actor made a word suggestion, and she would then repeat the word. However, after three rounds of team story-building, the youngest actor began to gain confidence in the pattern of the game, and she became more attuned to the narrative that was unfolding. On her fourth turn, she began to pick words on her own, and she quickly called out words without pause thereafter. She even began to make word suggestions during other actors' turns.

The game provided a space for the actors to do the challenging work of imagining and producing a narrative as a unified group and to build confidence with collaborative creative work, two outcomes which served our curricular goal of building a community. In order to create a coherent narrative, actors needed to listen, anticipate, and respond to the ideas of their peers and to simultaneously assert and moderate their own ideas according to the ever-changing direction of the narrative. This activity reflects the challenges one faces during the course of a dramatic performance as well as many social circumstances in which one must mediate between the will of others and the desires of the self.

After playing the story-building game, actors reviewed the plot of Midsummer and began a reflective writing activity. During the writing session, actors were encouraged to write ministories about a specific character's life after the end of the events of the play. One actor chose to write about Bottom's life and created a scenario in which Bottom, exhausted following the excitement of his transformation and dalliance with Titania, decides to settle down, marry, and raise a family. Accompanying this description of Bottom's life was a drawing of a house and a stick-figure family. When prompted, the actor explained, "Well, he's tired and wants a normal 
life." The writing activity encouraged actors to imagine beyond the bounds of the play. Actors identified specific events and emotions characters experienced during the course of the play and created expanded narratives in which those emotions and experiences had a direct impact on the character's future choices and actions. Together, the Team Story-Building game and the reflective writing activity encouraged the actors to imagine the possibilities beyond an existing text and to listen to each other and engage with character elements in order to expand and invigorate a narrative. Here we see the empathetic imagination at work. Actors were encouraged to consider the known aspects of a character's lifeworld, to wonder about the "hidden places" of that character's internal workings, and to engage with a number of different possibilities of human experience (Nussbaum 90).

\section{Translating, Eye-to-Eye}

Actors were encouraged to engage voice, emotion, and body in an acting game called Eye-toEye. During the game, pairs of actors staged arguments between a parent or adult and a child to gain deeper insight into the dynamic between Egeus and Hermia. Actors adhered to three rules: (1) actors could not touch one another during the argument, (2) actors could use their bodies and engage with props in order to express emotions relevant to their argument, and (3) actors had to maintain eye contact during the argument.

In one sketch a grandmother confronted her grandson for neglecting to take out the garbage. The grandson offered a host of reasons why he had not completed this chore: "I had to take care of my little brother. I had homework and football practice... I have too much to do around here!" The actor's volume intensified, and his pace quickened as he released this breathless litany. Irritated by her grandson's audacity and disrespect for authority, the actor playing grandmother responded in kind: "I take care of you when your parents work. Cook for you! Clean for you! Pick you up from school!" Grandmother inched closer to grandson with each declaration. Had a table not separated the actors, grandmother might have reached across it (or acted as if she would), before a peer from the audience intervened to stop her. The authenticity of sentiments and emotions present in this exchange so overwhelmed the spectator that she felt compelled to break the fourth wall. The spectator, great friends with both actors and a dedicated member of her acting community, revealed that she meant to protect her peers on stage: "I didn't want actor 1 to get in trouble for breaking the rules of the game [making physical contact] and I 
didn't want actor 2 to get hurt." As Nussbaum reminds us, imaginative spaces allow children to wonder. Storytelling provides opportunities to engage in empathetic relationships with others to build a sense of community. The spectator's intervention signaled a sympathetic responsiveness to another's needs - her friends on stage and fellow actors. Her efforts illustrated sincere investment in the troupe: a desire to preserve harmony informed her actions.

\section{Conflict/Resolution}

Translating A Midsummer Night's Dream's various conflicts for the actors was fairly straightforward. Like most Shakespearean comedies, the play opens with the perennial conflict between an older, father figure (senex) and the younger generation. In this case, we have Theseus who demands Hermia marry the man of his choosing rather than whom she has fallen in love with. The law, as one might suspect, aligns with the senex figure, and the generational conflict is made political as well as familial. The opening conflict promises rich material for young actors to feel their way through and explore because disagreement with authority figures plays a prominent role in their daily lives. Inspired by this scene and in preparation for performing it, actors were asked to reflect on conflicts they've experienced, how those encounters made them feel, and the strategies they did (or did not) use to resolve them. By using these experiences as an impetus for the aesthetic performance of a parent/child quarrel, actors were asked to recapture and simulate life experiences under the guise of safe, temporary play. Although The Puck Project did end in a culminating, public production of the play, day-to-day activities like these engage in what Gavin Bolton and Dorothy Heathcote have referred to as "fictional now time." The use of past experience to construct and simulate fictional encounters collapses the "now" of a present performance with the "then" of experience. When actors were asked to compose and act out scenes which involved imagined or recently experienced conflict, a number of them turned to issues of a friend's or parent's taking something away from them. Another great parallel to the play, this relational struggle marks the central conflict between Titania and Oberon, who are in a dispute regarding a found changeling boy. In the play, this issue has cosmic consequences, but for our actors, we translated it into the theft and reclamation of a magical harp. In our adaptation, Titania is furious at Oberon for taking the harp and refusing to return it, not unlike the confrontations the actors wrote, acted, and journaled on. 
What was unexpected, however, were the ways the actors' lived experience would translate into refreshing ways of reading and understanding the play's narrative arc and character development. The actor who played Helena, for example, spent extra time considering the motivations, anxieties, and desires of her character, often mapping her own lived experience onto her performance of the part. Helena's beginning is one of unrequited and shunned desire for Demetrius, who, is in love with Hermia, Helena's close friend. The awkwardness that comes with youth is readily transferable between actor and part in this case, but Helena's actor, in particular, reflected on the ways in which unreturned or shunned love for another might be just as much a part of her relationship with her friend as it is with Demetrius himself. In a postrehearsal reflection, we asked the actresses to what extent they identified with amorous predicament. In this case, the actresses playing Hermia and Helena were close friends and their friendship outside the context of the play informed the way they portrayed the characters. The actress playing Helena reflected on the adapted lines: "Do you have no shame? No dignity left? Are you trying to make me so angry that I will respond with insults rather than my usual gentleness?" She challenged the antagonism between Helena and Hermia with her own script for female friendship: "I actually wouldn't say this. If my best friend and I liked the same boy, I would let her have him. I'd just want my friend back." Through this performance, the play's preoccupation with the Helena-Demetrius conflict is de-centered and subsumed into the possible internal doubts and competition among friends. As Daniel Kelin notes, "By creating a parallel journey to a story, the [actors] come to see and experience the story from the inside, emotionally and imaginatively connecting with the characters and making the story their own" (283). We knew, of course, that performance involved discomfort — par for the course in acting — but what was unexpected was how specific roles might be embodied in ways that reveal and reflect on an actor's place in life or in the world.

As emerging literary scholars, we recognize and appreciate the fact that representation matters. When children immerse themselves in the arts, they ought to see characters who not only look like them but also experience similar dilemmas. For us, as arts practitioners and for our young actors, this self-reflexivity is an act of translation. After the final performance, we asked the actors if they saw themselves in the characters they played that day. The actor who played Bottom responded by saying, "Sort of. What I don't like about him is that he doesn't have a lot of parts. What I do like about him is he's unique, cool, being himself. When he becomes a 
donkey, it's funny, but when Bottom turns back into a human, he's himself again. I feel relief. When I meet new people, I try not to be myself because I want them to like me. Being myself sometimes is weird. People say I'm weird. Weird people, they just be themselves." After weeks of rehearsal, the actor's want for more parts echoes his character's own desires. He finds in his character an aspirational quality: comfort in one's own skin. The actor must imagine the emotional turmoil of Bottom's forced translation from man to donkey, finding relief only in the restoration of the self. In imagining this forced translation, the actor expresses a desire to return to the self as Bottom, which in turn prompts a reassessment of his own unique qualities. It's through the experience of performance that the actor simulates the other to find and affirm the self.

\section{Works Cited}

Barton, Bob, and David Booth. Stories in the classroom: Storytelling, reading aloud and Roleplaying with children. Heinemann, 1990.

Berry, Cecily. The Actor and the Text. Virgin Books, 1993.

Bolton, Gavin M., and Dorothy Heathcote. So You Want to use Role-Play? A New Approach in How to Plan. Trentham, 1999.

Butler, Judith. Undoing Literature. Routledge, 2004.

Case, Gretchen A., and Daniel J. Brauner. "The Doctor as Performer: A Proposal for Change Based on a Performance Studies Paradigm.” Academic Medicine, vol. 85, no. 1, 2010, pp. 159-163.

Chall, Jeanne. Stages of Reading Development. McGraw Hill, 1983.

Cheng, Astrid Yi-Mei, and Joe Winston. "Shakespeare as a second language: playfulness, power and pedagogy in the ESL classroom." RiDE: The Journal of Applied Theater and Performance, vol. 16, no. 4, 2011, pp. 541-56.

Coles, Jane. "Every child's birthright'? Democratic entitlement and the role of canonical literature in the English National Curriculum." The Curriculum Journal, vol. 24, no. 1, 2013, pp. 50-66.

Frank, Judith. "In the Waiting Room: Canons, Communities, "Political Correctness." Wild Orchids and Trotsky: Messages from American Universities, edited by Mark Edmundson, Penguin, 1993, pp. 125-49. 
Fuchs, Thomas, and Sabine C. Koch. "Embodied affectivity: on moving and being moved." Frontiers in Psychology, vol. 5, 2014, pp. 1-12.

Gibson, Rex. Teaching Shakespeare. Cambridge University Press, 1998.

Grossman, Edith. Why Translation Matters. Yale University Press, 2010.

Herdt, Jennifer A. “Alasdair MacIntyre's 'Rationality of Traditions' and Tradition-Transcendent Standards of Justification.” Journal of Religion, vol. 78, no. 4, 1998, pp. 524-546.

Holland, Chris. "Reading and acting in the world: conversations about empathy." RiDE: The Journal of Applied Theater and Performance, vol. 14, no. 4, 2009, pp. 529-544.

Huang, Alexander C. Y. "Shakespeare and Translation." The Edinburgh Companion to Shakespeare and the Arts, edited by Mark Thornton Burnett and Adrian Streete, Edinburgh University Press, 2011, pp. 68 - 87.

Jakobson, Roman. “On Language Aspects of Translation.” The Translation Studies Reader, edited by Lawrence Venuti, $2^{\text {nd }}$ ed., Routledge, pp. 138 - 43.

Kelin, Daniel A. “The Perspective From Within: Drama and Children's Literature.” Early Childhood Education Journal, vol. 35, 2007, pp. 277-284.

Lillard, Angeline Stoll. "Playing with a theory of mind." Multiple Perspectives on Play in Early Childhood Education, edited by Oliva N. Saracho and Bernard Spodek, SUNY Press, 1998, pp. $11-33$.

Neuman, Susan B. and Kathleen Roskos. "Play as an opportunity for literacy." Multiple Perspectives on Play in Early Childhood Education, edited by Oliva N. Saracho and Bernard Spodek, SUNY Press, 1993, pp. 100-115.

Nussbaum, Martha C. Cultivating Humanity. Harvard University Press, 1997.

Schechner, Richard. Between Theater and Anthropology. University of Pennsylvania Press, 2011.

Shakespeare, William. A Midsummer Night's Dream. The Norton Shakespeare. $3^{\text {rd }}$ ed., W. W. Norton \& Company, 2016.

Sponseller, Doris Bergen. Play as Medium for Learning and Development: A Handbook of Theory and Practice. Heinemann, 1988.

Turner, Victor. The Anthropology of Performance. PAJ Publications, 1988. 
Whitehurst, Grover J. and Christopher J. Lonigan. "Child Development and Emergent Literacy." Child Development, vol. 69, no. 3, 1998, pp. $848-872$.

Wiggins, Grant, and Jay McTighe. Understanding by Design. $2^{\text {nd }}$ ed., Association for Supervision \& Curriculum Development, 2005.

Wilhelm, Jeffrey D., and Brian Edmiston. Imagining to Learn: Inquiry, Ethics, and Integration Though Drama. Heinemann, 1998.

Youngquist, Joan, and Jann Pataray-Ching. "Revisiting 'Play': Analyzing and Articulating Acts of Inquiry." Early Childhood Education Journal, vol. 31, no. 3, 2004, pp. 171-78.

\section{Notes}

1 “"Every child's birthright'? Democratic entitlement and the role of canonical literature in the English National Curriculum," The Curriculum Journal, 24.1 (2013): 50-66. Similar complaints show up in public discourse as well, such as Ralph E. Schaffer, "Reading Shakespeare: Something is rotten in Common Core," Chicago Tribune (2014) and Rajat Bhageria, "Why Do We Force Students to Read Shakespeare?," The Huffington Post (March 2015).

${ }^{3}$ See Bermann for a similar reading of performed and interpretive translations of Dante's Inferno.

${ }^{4}$ Shakespeare Behind Bars "offers theatrical encounters with personal and social issues to incarcerated, postincarcerated, and at-risk communities" (www.shakespearebehindbars.org). Feast of Crispian is "a non-profit organization that brings professional actors and veterans together to strengthen the emotional resources they need to overcome trauma and reintegration issues" (www.feastofcrispian.org).

${ }^{5}$ Approximately one quarter of the actors may be categorized as "early fluent" or "emergent readers." These actors possessed the skills, knowledge, and attitudes that are developmental precursors to reading and writing (e.g.

phonological awareness, letter knowledge, a command of high-frequency words). The term also refers to a point of view about the importance of "social interactions in literary-rich environments for prereaders and to advocacy for related social and educational policies (Whitehurst and Lonigan, 848-9). The remaining actors fell within "fluent" or "transitional" reading stages. Actors in these stages are "reading for learning the new." While they may lack specific world knowledge, vocabulary, and limited cognitive abilities, they can access materials that are clear, within one viewpoint, or texts with limited technical complexities (Chall, 10-24).

${ }^{6}$ See Bolton, G. and Heathcote, D. So You Want to Use Role-Play? A New Approach in How to Plan (Trentham, 1999) for their discussion of "fictional now time." 